\title{
O nascimento da sociologia na universidade francesa (1880-1914)
}

Laurent Mucchielli

CNRS - Revue d'Histoire des sciences humaines

RESUMO

Este artigo apresenta de modo sintético o percurso pelo qual a sociologia se tornou uma disciplina universitária no decorrer dos séculos XIX e XX. Interroga-se aqui de início a evolução institucional e a profissionalização das ciências humanas nas décadas finais do século XIX. Em seguida, é abordada a importância do contexto político-intelectual (a Terceira República, o avanço do socialismo, o Affaire Dreyfus). Diante disso, o artigo aborda a vida interna desse novo campo de conhecimento. Esse percurso é ritmado no final do século XIX pela concorrência que lhe opõem vários atores ou grupos de atores. Por meio dessa jornada e da rivalidade que opôs três homens (Émile Durkheim, Gabriel Tarde e René Worms), colocaram-se também como oponentes três estratégias intelectuais e três redes sociais.

Palavras-chave: Durkheim; Tarde; Worms.

\section{ABSTRACT}

This article is in a synthetic analysis of the way sociology has became an academic discipline at the turn of the $20^{\text {th }}$ century. It first focuses on its institutional developments and on the professionalization of the human sciences during the last third of the $19^{\text {th }}$ century. It then emphasizes the weight of the political and intellectual context (the Third Republic, the rise of Socialism, the Dreyfus Affair). Within this framework, the paper finally concentrates on the internal life of this new field of knowledge. This life is punctuated by the competition opposing social actors of groups of actors. Through the professional courses and rivalries opposing three men (Émile Durkheim, Gabriel Tarde and René Worms), are also disclosed three intellectual strategies and social networks.

Keywords: Durkheim; Tarde; Worms. 
Antes de discutir as grandes linhas do nascimento da sociologia na universidade francesa será apresentada uma reflexão sobre o método em história das ciências humanas. ${ }^{1}$ De fato, a apresentação que se pode construir de tal assunto depende das escolhas metodológicas feitas e que são, muitas vezes, implícitas.

Três convicções metodológicas guiam este trabalho: a ultrapassagem da oposição entre a história das idéias e a sociologia das ciências; a problematização da noção de "disciplina"; a prática de uma história "historicizante", isto é, de uma história contextualizadora, que não somente considera as dimensões culturais, sociais e políticas, mas também procura efetivamente articulá-las com a produção intelectual.

\section{História das idéias e sociologia das ciências}

Há quase trinta anos, nos países anglo-saxões, mais recentemente na França, a oposição às insuficiências da história das idéias é reivindicada pela sociologia das ciências. Muitas vezes, esta oposição se apresenta de maneira radical. De um lado, a sociologia das ciências contesta a possibilidade de existência de conteúdos do pensamento científico não redutíveis socio-culturalmente, ou então perde o interesse por eles. De outro lado, a história das idéias e a filosofia das ciências herdadas de Bachelard e de Popper não analisam a produção e a recepção social das idéias científicas, consideram somente seus procedimentos internos de argumentação e de validação. Há aí dois impasses metodológicos em relação aos fatos históricos a serem considerados.

A história das idéias científicas, consideradas in abstracto, isto é, fora de todo contexto social (imediato) ou cultural (de mais longa duração) e fora de toda função outra que a produção da verdade científica, parece uma ilusão perigosa de filósofos. Ela leva a fazer a história pelo avesso, a esvaziar os textos de uma grande parte do seu sentido e a retirar deles a maior parte da história das ciências para se interessar apenas por uma pequena parte do que é considerado como a verdade em devir. Com tal afirmação, não nos reconhecemos tampouco em certas outras propostas sociológicas. Por certo, o princípio segundo o qual toda a produção intelectual deve ser considerada no seu contexto social de produção constitui algo já assentado. A idéia é antiga. Nos Estados Unidos, os sociólogos e os historiadores das ciências, defendem esse princípio desde os anos 
1950, em torno notadamente das noções de comunidade e de mercado científicos.

Na França, é a noção de campo científico, proposta nos anos 1970 por Bourdieu, que teve durante muito tempo maior êxito. Entretanto, considera-se parcialmente redutoras as afirmações que desde esta época propõem uma visão econômica e ao cabo de tudo muito individualista, de uma atividade científica concebida na forma de um mercado concorrencial, no qual o pesquisador comportar-se -ia de maneira unicamente utilitarista, com o propósito de maximizar seus ganhos simbólicos a fim de conquistar reconhecimento, legitimidade e poder. Esta situação existe, é evidente, mas a atividade científica não se esgota aí; o problema da criação intelectual, por exemplo, permanece aberto: as estruturas sociais podem levar a ela, mas por que tal indivíduo, em tal momento e sob tais formas?

Da mesma maneira, não se pode verdadeiramente explicar todos os elementos da realidade observada situando simplesmente esses indivíduos no quadro muito geral das instituições científicas que são notadamente as universidades. A idéia de que as posições institucionais são determinantes no curso da vida científica tornou-se um verdadeiro lugar-comum, do qual deve-se desconfiar no decorrer da pesquisa. Parece particularmente importante contestar a idéia de que a vida intelectual não é senão o reflexo da vida institucional.

Da mesma maneira ainda, separamo-nos dos sociólogos ditos da escola de Edimburgo quando reduzem as controvérsias a relações de força no seio da instituição científica, relações nas quais a força de persuasão própria das idéias não desempenharia papel algum ( força de persuasão que teria que ser ela própria explicada, mas igualmente com elementos de história cultural e não por uma simples sociologia do poder). E mesmo se algumas situações redutíveis a relações de força podem existir serão de fato generalizáveis? Não o cremos. O exemplo da " luta a três" (match à trois, n.t.) que caracterizou o nascimento da sociologia universitária francesa parece significativo desse ponto de vista.

$\mathrm{Na}$ realidade, se as estratégias individuais são importantes (mas não redutíveis a uma simples busca de prestígio) e se os quadros gerais da atividade social exercem múltiplas imposições gerais, a dinâmica da atividade científica é antes de tudo devida a pequenas coletividades que se situam num plano de análise intermediário entre os indivíduos e as instituições. Entre esses, existem grupos sociais intermediários cujo peso é capital: são as redes. Não importa a denominação (rede, grupo, equipe, círculo, laboratório, escola, colégio invisível, etc.), existe aí um objeto fundamental 
para o historiador e o sociólogo das ciências (conforme Mullins, Clark, Crane, Geison, etc.). Nenhum sucesso e nenhuma derrota são compreendidos na sua ausência. Mais simplesmente ainda, nenhum empreendimento científico importante pode existir sem ele. Os famosos "pais fundadores", como Durkheim ou Freud, não teriam conhecido tal consagração não em todo caso em vida e, mesmo depois, não em tamanhas proporções - não tivessem sido chefes de escola, isto é, se os seus discípulos ou colaboradores não se tivessem encarregado direta ou indiretamente de legitimar e difundir suas idéias, suas memórias, suas heranças.

\section{Uma história pluridisciplinar}

De maneira geral, os primeiros historiadores da psicologia foram psicólogos, os primeiros historiadores da sociologia, sociólogos, os primeiros historiadores da geografia, geógrafos, etc. Fizeram um trabalho considerável. Porém, na perspectiva do historiador "generalista", o viés mais imediato e mais óbvio da história de uma disciplina reside nas numerosas reduções que impõem a própria noção de disciplina. Na França, em muitos casos, a autonomização definitiva e completa dos currículos universitários não se realizou senão na segunda metade do século XX. Durante muito tempo, as fronteiras disciplinares foram muito mais permeáveis do que a observação dos últimos trinta anos permite supor. Até esta data, era freqüente ver, por exemplo, um sociólogo intervir numa sociedade de psicologia, numa revista de economia, num congresso de etnologia, ou ainda numa banca de tese de filosofia. Durante longo tempo a lógica do objeto (ou lógica da aproximação do objeto) prevaleceu sobre a lógica disciplinar (ou lógica da especialidade). Assim, as influências intelectuais, tal como as redes de solidariedade ou de interesse entre os atores transcendiam amplamente as divisões institucionais. Reduzir as obras a uma dimensão disciplinar, a uma problemática disciplinar, significa portanto mutilá-las.

Em suma, não se pode mais escrever a história longínqua de uma disciplina, qualquer que seja ela. Na medida em que esta própria noção se tornou um objeto e um problema historiográfico, pode-se escrever somente a história do processo de disciplinarização. Eis porque é indispensável trabalhar com as fronteiras disciplinares, sobre as trocas conceituais, metodológicas, metafóricas, e sobre as bases sociais destas circulações de ho- 
mens e de idéias: as redes de atores, as revistas, as sociedades científicas, os congressos nacionais e internacionais.

\section{Uma bistória "bistoricizante", isto é, contextualizadora}

A história disciplinar, como a história epistemológica que Bachelard e seus alunos praticavam, produz muitas vezes problemáticas que poderiam ser qualificadas de genealógicas, que consistem em retraçar a origem e a evolução dos conceitos, em trabalhar de maneira privilegiada os grandes autores reputados "fundadores", em discutir a anterioridade de tal ou qual teoria. Ora, mesmo se estas problemáticas são legítimas e indispensáveis, sofrem geralmente do defeito próprio à interrogação retrospectiva quando esta se torna na realidade, por uma tendência bastante natural do espírito, uma reconstrução a partir do presente. Chega-se então a esta postura metodológica que se chama, após Georges Stocking, o presentismo. A ilusão de isolamento e de gênio criativo do "pai fundador", a comparação "sob forma de aproximação ou de oposição" de conceitos e de métodos elaborados, entretanto, em lugares diferentes, em face de interlocutores diferentes e com objetivos diversos, a continuidade posta em evidência entre autores separados por várias décadas até mesmo por mais de um século, porque empregam os mesmos conceitos (mas cuja semântica e lugar no conjunto do aparato conceptual podem ser bastante diferentes), tais são os vieses metodológicos os mais recorrentes do presentismo. Nenhuma disciplina escapou a isso. Os próprios historiadores sustentaram por longo tempo o seu próprio mito fundador em torno da escola dos Annales.

Inversamente, ser historicista, ou simplesmente historiador, é compreender que os textos têm contextos, que os discursos foram pensados e pronunciados direcionados para um auditório, que os artigos e os livros foram pensados e escritos direcionados para um público leitor, que os grandes homens, sem exceção, tiveram professores e não inventaram tudo, reproduziram como os outros os preconceitos e os estereótipos culturais os mais gerais de sua época, tiveram as mesmas fraquezas narcísicas (muitas vezes mais do que os outros!), em suma, foram simplesmente homens e, mais ainda, homens de seu tempo.

Por todas estas razões, esforçamo-nos em fazer uma história das ciências que restitui questões sociais, políticas, tanto quanto intelectuais, uma história que considera os quadros culturais coletivos e que situa todo autor, todo texto no quadro dos debates das comunidades científicas de sua 
época. Nesta óptica, é essencial proceder não somente à análise da integralidade das obras individuais (incluídos os textos freqüentemente muito reveladores que são as resenhas), mas também à verificação minuciosa das revistas, dos boletins das sociedades científicas e de todas as outras manifestações da vida cotidiana destas comunidades. Somente tentando restituir o conjunto destas interações e destes contextos se pode esperar compreender todos os significados dos textos científicos.

\section{NASCIMENTO DA SOCIOLOGIA UNVERSITÁRIA NA FRANÇA ${ }^{2}$}

Incontestavelmente, nos anos 1880-1900, assistiu-se na França ao aparecimento massivo de autores e de grupos de autores que reivindicavam o rótulo de sociólogos, que procuravam autonomizar esta ordem de saber das abordagens preexistentes e que tentavam desenvolver este ensino no seio da universidade. Foi o momento decisivo.

Por certo, o princípio da existência de uma nova ciência batizada de Sociologia foi estabelecido já em 1856 por Auguste Comte, na 47를 Lição do Curso de Filosofia Positiva. Do mesmo modo, a primeira Sociedade de Sociologia foi fundada em 1872 por Émile Littré, o líder dos discípulos não-religiosos de Comte ${ }^{3}$. Essa sociedade contava com médicos, juristas e filósofos. Porém, periclitou muito rapidamente, por falta de participantes e também de algum tipo de consenso sobre a definição, o programa e os métodos desta nova ciência. De um modo geral, a influência universitária do positivismo declinou na França após a morte de Littré (1881) e o desaparecimento de sua revista La philosophie positive. Nos anos 1880, Spencer e o evolucionismo concentravam toda a atenção ${ }^{4}$. Não houve assim continuidade direta entre a tradição positivista e o nascimento da sociologia universitária. A inovação proveio, na realidade, de uma outra geração intelectual. Para compreender o nascimento da sociologia universitária em toda a sua complexidade, pode-se fazer um rápido inventário dos fatores sociais, políticos e culturais que para ele contribuíram de múltiplas maneiras ${ }^{5}$. Note-se que a enumeração apresentada não resulta em hierarquia particular, pois os diferentes fatores são implicados de maneira diferente segundo as trajetórias dos autores.

As transformações do campo universitário e a profissionalização das ciências humanas

A autonomização paradigmática das ciências humanas foi amplamente facilitada pela autonomização universitária destes saberes 6 . É pre- 
ciso em primeiro lugar assinalar a importância da criação da École Pratique des Hautes Études (EPHE) no final do Segundo Império (1864 e anos seguintes). Esta nova instituição continha na origem quatro seções; apenas a 4- interessa às ciências humanas: a seção das ciências históricas e filológicas. Em 1885, nasceu todavia uma $5^{\underline{a}}$ seção para as ciências religiosas (seção que desempenhará um papel importante no grupo de Durkheim). A economia política conquistou então sua autonomia no seio das faculdades de Direito ${ }^{7}$. Enfim, conduzido por um personagem muito importante ( Louis Liard, diretor do ensino superior entre $1884 \mathrm{e}$ 1902), o desenvolvimento das faculdades de Letras desempenhou um papel essencial. De fato, permitiu a criação de cursos para as novas ciências humanas. Duas inovações foram particularmente notadas na época: o curso de Psicologia criado em 1885 por Théodule Ribot em Paris, e o curso de Ciência Social criado por Émile Durkheim em 1887 em Bordeaux.Este desenvolvimento das faculdades de Letras acompanhou-se também de uma profissionalização dos públicos. Os anfiteatros acolhiam maior número de estudantes que se beneficiavam em especial de bolsas cada vez mais numerosas a partir de 1877 . No total, havia quinze mil estudantes no conjunto das universidades francesas em 1880, serão quarenta mil à véspera da Primeira Guerra Mundial.

Este movimento de crescimento e diversificação institucionais induziu rapidamente um movimento de profissionalização que se traduziu em particular pelo surgimento de novas revistas. Às revistas gerais acolhendo textos de autores de estatutos os mais diversos, juntavam-se ou substituiram-se revistas especializadas das quais participavam principalmente universitários: Revue Historique em 1876, Revue de l'bistoire des religions em 1880, Revue d'ethnographie em 1882, Archives d'anthropologie criminelle em 1886, Revue d'économie politique em 1887, Annales de géographie em 1891, Revue internationale de sociologie em 1893, Annéepsychologique em 1894, Année sociologique em 1898, Revue d'bistoire moderne et contemporaine em 1899, Notes critiques/Sciences sociales em 1900, Journal de Psychologie em 1904, etc.

\section{O contexto político-intelectual}

Quando se afirma que a sociologia nasceu na França em torno de 1880-1900, é difícil não perceber que se trata muito exatamente dos anos de fundação da Terceira República e, em seguida, da instalação do que hoje é chamado o Estado de bem-estar ${ }^{8}$. Por isso, é importante interrogar-se 
sobre o conteúdo da ideologia republicana desta época, sobre as idéias, os valores partilhados pela geração que acompanha este evento político de importância considerável. O que se passa, pois, no plano das ideologias políticas nesses anos 1880-1900? Quatro elementos parecem determinantes. Em primeiro lugar, o advento da República acompanhou-se da idéia de programa da transformação da sociedade, portanto, do seu conhecimento científico, da descoberta de leis que presidiriam o destino das sociedades. É uma idéia encontrada praticamente em todos os sociólogos franceses da época, quaisquer que sejam suas referências filosóficas (positivismo, evolucionismo, etc.). Deve-se observar que este momento coincidiu também com a generalização do uso das estatísticas em ciências humanas. O papel intelectual e institucional do demógrafo Jacques Bertillon foi aqui importante (ele fundou, por exemplo, o Institut international de statistique em 1885). Entre os novos sociólogos, o uso das estatísticas para colocar em evidência as leis de funcionamento da sociedade eram habituais. Pensemos em Tarde para a criminalidade (será, outrossim, nomeado em 1894 para a direção da estatística judiciária no Ministério da Justiça). Pensemos em Durkheim em O suicídio (1897). Pensemos nos trabalhos de Simiand e de Halbwachs em sociologia econômica.

Em segundo lugar, a crise que a Terceira República conheceu a partir de 1885 (em razão, por um lado, da crise econômica e do ascenso do socialismo no plano interno; por outro lado, das dificuldades nas colônias no plano externo) e levou os governos que sucedem ao de Jules Ferry a procurar uma nova coerência ideológica, uma nova política geral. Muitos republicanos a encontravam naquilo que Léon Bourgeois chamou nos anos 1890 "solidarismo", a ideologia da solidariedade. De fato, foi a época em que se instalou na França o Estado de bem-estar, caracterizado em particular pelo reforço do direito do trabalho, da assistência médica, do princípio geral da seguridade social. Este contexto político é muito importante. Tentei mostrar em outro lugar como este contexto havia condicionado a recepção de Spencer na França ${ }^{9}$. Após ter sido o filósofo mais importante e um modelo na França nos anos 1870-1885, porque encarnava a idéia de ciência e de evolução, tornou-se rapidamente um adversário porque encarna doravante o ultra-liberalismo, o darwinismo social, a oposição ao Estado de bem-estar e a idéia de solidariedade ${ }^{10}$. Isto é importante para a compreensão de certas análises de Tarde, e sobretudo de todo o projeto de Durkheim em sua tese sobre a Divisão do trabalho social (1893). Durkheim foi considerado de fato, na época, como a principal referência científica do solidarismo ${ }^{11}$. 
Em terceiro lugar, os anos 1885-1900 são os do fortalecimento do socialismo no mundo operário e também na juventude intelectual francesa $^{12}$. Este foi introduzido muito especialmente na École Normale Supérieure (ENS) pelo bibliotecário Lucien Herr. Foi ele quem introduziu a leitura de Marx e dos socialistas alemães entre numerosos jovens filósofos, no meio dos quais Jean Jaurès. Muitos normaliens desta época, filósofos e historiadores, tornaram-se socialistas seguidores de Jean Jaurès em um grande número de instituições menores. Este fator político criou naturalmente solidariedades particularmente fortes entre os indivíduos. Veremos que o sucesso da equipe de Durkheim esteve ligado em parte a esta coerência ideológica, sobretudo depois do caso Dreyfus.

De fato, o evento político marcante do fim do século XIX na França foi o caso Dreyfus ${ }^{13}$. Contrariamente ao que aconteceu nas faculdades de Direito ou de Medicina, a nova geração dos normaliens que ensinou nas faculdades de Letras era majoritariamente partidária de Dreyfus. A adesão dos socialistas trazidos por Jaurès foi igualmente muito importante. $\mathrm{O}$ encontro destes dois combates políticos e filosóficos de fato deu uma coesão particularmente forte a seus partidários e atenuou as críticas daqueles a quem o socialismo amedrontava. Os laços pessoais entre os membros da equipe de Durkheim e seus laços com grande número de antigos companheiros da ENS foram consideravelmente reforçados durante e após o caso Dreyfus. Ademais, este contexto político teve conseqüências diretas sobre o debate científico. Notadamente diminuiu a legitimidade da antropologia racial e dos discursos apologéticos da desigualdade. Se o que produz o fundamento da pertença a uma sociedade não é a raça, a fisiologia, então o que é? É a cultura, são as crenças, os modos de pensar, os valores. Uma sociedade é um espírito coletivo, uma "consciência coletiva”, como dirá Durkheim após outros. Em 1882, Renan avançava já a idéia em sua célebre conferência intitulada "O que é uma nação?” No fim do século XIX tornou-se uma idéia banal.

\section{A autonomização do campo da sociologia}

Nas décadas que precederam o nascimento da sociologia universitária, o estudo científico das condutas humanas era sobretudo tarefa das ciências biomédicas: antropologia, psiquiatria, psicofisiologia. Globalmente, estas ciências funcionavam no quadro de um paradigma naturalista, explicando os comportamentos sociais pela natureza biopsicológica dos indivíduos e dos grupos de indivíduos. As noções de raça, heredita- 
riedade, constituição cerebral, são centrais nestas abordagens que consideram as sociedades como somas de indivíduos.

Os anos 1860-1890 foram o momento de apogeu destes modelos naturalistas aplicados às ciências sociais. Em psiquiatria dominavam as teorias da degenerescência ${ }^{14}$. A psicofisiologia foi desenvolvida por Ribot, Richet e muitos outros no quadro do naturalismo ${ }^{15}$. A antropologia racial foi consideravelmente reforçada e institucionalizada por Paul Broca, que se tornou célebre por suas pesquisas sobre as localizações cerebrais das funções intelectuais e daquelas ligadas à fala, mas que não foi menos importante, na época, para a antropologia geral ${ }^{16}$. Após ter criado a Sociedade Antropológica de Paris em 1859, Broca fundou em 1875 a Escola Antropológica de Paris, onde Letourneau ensinou sociologia sobre a base teórica da antropologia racial (ele publica La sociologie d'après l'ethnographie em 1881). Gustave Le Bon e Georges Vacher de Lapouge formaram-se igualmente nesta corrente. Uma antropologia criminal desenvolveu-se igualmente sob a direção de Alexandre Lacassagne no quadro das teorias hereditárias (que preferem simplesmente o modelo da degenerescência ao do atavismo divulgado pelo italiano Cesare Lombroso). Ele fundou em 1886 os Archives d'anthropologie criminelle ${ }^{17}$.

Entretanto, a partir de meados dos anos 1880, em função do conjunto de razões sociais, políticas, culturais e filosóficas, apareceram novas abordagens que romperam amplamente com o biologismo. A primeira grande reação foi a de Gabriel Tarde (1843-1904), que criticou fortemente os evolucionistas, darwinistas sociais e biocriminólogos italianos, desenvolvendo por sua vez uma "interpsicologia" fundada sobre o modelo psicológico da hipnose que chamou de "imitação" ${ }^{18}$. A segunda reação foi a de Émile Durkheim (1858-1917), que pretendeu romper mais radicalmente ainda com o conjunto das abordagens tradicionais e instituir uma sociologia que repousava também sobre uma filosofia e uma psicologia do homem em sociedade. A associação dos homens em sociedade produz, segundo ele, fenômenos novos, fenômenos propriamente sociais que reclamam instrumentos de análise e de interpretação específicos. No ínterim, surgiu todavia uma terceira personagem - Rene Worms (1867-1956) -, que tentou adiantar-se a todos dotando a sociologia de suas primeiras instituições ${ }^{19}$. Mas ele também cria na possibilidade de reativar a velha teoria do organicismo, deixando de efetuar portanto a ruptura com o paradigma naturalista. No essencial, nesta luta a três se deu a conquista da liderança da nova sociologia. 


\section{A Peleja entre Worms, TARdE E Durkheim}

Dos três pretendentes, quem irá dominar a nova disciplina? Cada um utilizou meios diferentes, conforme sua própria trajetória intelectual e profissional. Cada um dispôs de trunfos diferentes e o resultado desta peleja foi incerto durante doze anos, entre 1890 e 1903 aproximadamente.

As forças em presença

Worms seguiu uma estratégia puramente institucional, pois foi o primeiro a tentar a fundação da sociologia em instituições. Trata-se de um agrégé de direito e filosofia, filho de um jurista conhecido, mas por falta de documentos pessoais é difícil saber o que o teria levado a lançar-se na aventura da sociologia. Permanece o fato de que tentou e conseguiu fundar os primeiros assentamentos institucionais da sociologia em tempo muito reduzido, tanto que em 1893 fundou a Revue Internationale de sociologie (que organizará congressos anuais) e em 1895 a Sociedade de Sociologia de Paris. Para garantir o êxito em seu golpe de força institucional, Worms aliou-se aos antropólogos da Sociedade de Antropologia de Paris e com juristas. Enfim, esforçou-se em promover o desenvolvimento da nova sociologia nas faculdades de Direito, seguindo o modelo da economia política.

A primeira vista, seu empreendimento foi um êxito pois a revista não tinha nenhuma dificuldade em encontrar autores, os congressos atraíam de fato o establishment do momento e publicava atas não menos alentadas; enfim, a Sociedade de Sociologia (cujo primeiro presidente será Tarde) punha em cena todos os sociólogos franceses do momento à exceção de Durkheim e seus mais próximos colaboradores.

Quanto a Tarde, adquiriu um prestígio solitário ${ }^{20}$.Jurista de formação e juiz de instrução em sua primeira profissão, ele era também um apaixonado de criminologia e filosofia, que se distinguiu rapidamente na cena intelectual por duas razões. Primeiramente, nos anos 1880, foi um dos primeiros e sem dúvida o mais ardente opositor das teorias biológicas da criminalidade de Lombroso. Além disso, se opôs muitas vezes ao naturalismo, notadamente ao organicismo e ao darwinismo social de Spencer, portanto deste ponto de vista, ele era coerente com o contexto ideológico.

Tarde foi também muito coerente com a moda científica do momento, pois o cerne de sua obra teórica consistiu, com efeito, em importar 
para a sociologia uma descoberta de psicologia dos anos 1880: a hipnose e a sugestão ${ }^{21}$. Trata-se de uma velha história (lembre-se de Mesmer e sua teoria do magnetismo animal) que atravessou todo o século XIX mas que teve o reconhecimento acadêmico a partir de 1882, com a intervenção de Charcot na Academia de Ciências, e que alcançou um impulso sem precedentes nos anos seguintes. Revistas, congressos, sociedades científicas: toda uma série de instituições se posicionam nos anos 1880 em torno desses temas.

Além da oposição bem conhecida entre Charcot e Bernheim, a maior parte dos psicofisiólogos e psicopatólogos da época trabalharam com este objeto: Charles Richet, Alfred Binet e Pierre Janet, por exemplo. Isto explica largamente o sucesso da adaptação de Tarde, da qual o livro Les lois de l'imitation (1890) foi o ponto culminante. Este livro conheceu um grande sucesso, na França e no exterior. Na época, foi sem dúvida o maior best-seller de sociologia na França, com os Princípios de sociologia de Spencer. De fato, nos anos 1890-1900, Tarde conheceu a consagração acadêmica: convidado em todos os congressos, associado por Lacassagne à direção dos Archives d'anthropologie criminelle, tornou-se professor da Escola Livre de Ciências Políticas (fundada em 1871 por Emile Boutmy), nomeado para a direção da estatística judiciária no Ministério da Justiça, e enfim eleito para o Collège de France em 1900, bem como para a Academia de Ciências Morais e Políticas. Nessa época, embora fosse o sociólogo francês mais conhecido, permaneceu um intelectual solitário que não procurava verdadeiramente promover a sociologia na universidade.

\section{A força da equipe de Durkheim}

Durkheim foi o último a chegar nesta história. A sociologia era para ele uma vocação pessoal e uma missão política no sentido mais nobre, a ciência que iria permitir a compreensão da crise social e moral da sociedade francesa e indicar os remédios para restabelecer a solidariedade entre os membros da sociedade, a ciência do Homem por excelência. Nesse sentido, ele foi fiel à tradição de Saint-Simon e Comte (mesmo de Montesquieu, a quem ele consagrou sua tese secundária). Sua filosofia repousa sobre o dualismo do homem físico e do homem moral (isto é, social), herdando muito de Charles Renouvier, bem como de seu professor na ENS, Émile Boutroux.

Em sua tese sobre a Divisão do trabalho social (1893), Durkheim se posicionou antes de tudo contra Spencer, contra o individualismo e o natu- 
ralismo. O homem é homem porque é um animal social, sua natureza humana é constituída de tudo o que apreende da sociedade que o educa. Como Tarde, Durkheim foi muito coerente com o contexto ideológico dos anos 1885 e seguintes. No entanto, ele demorou em obter o reconhecimento completo de seus pares e a consagração acadêmica. Muitas vezes ignora-se que a ascensão de Durkheim foi muito dificultada no início. Sem dúvida, normalien, agrégé de filosofia, seus primeiros artigos sobre a filosofia e as ciências sociais na Alemanha lhe trouxeram de imediato uma reputação muito boa. Além disso, em 1887, Liard criou para ele o primeiro curso de sociologia numa faculdade de Letras (Bordeaux). Em seguida, sua tese confirmou sua reputação e o lugar de quase igualdade com Tarde. Entretanto, sua obra seguinte, As regras do método sociológico (1895), foi um fracasso importante, de fato, muito mal recebido na comunidade intelectual francesa. Durkheim conseguiu porém restabelecer sua autoridade graças à sua obra seguinte, O suicídio (1897), que foi, pelo contrário, muito bem recebida e cujo aparato estatístico impressionou muito a maior parte de seus contemporâneos.

Mais ainda, durante os anos de 1896 e 1897, Durkheim empreendeu a formação de uma equipe de jovens sociólogos, ${ }^{22}$ e com muito esforço lançou em 1898 uma nova revista que foi um sucesso: Année sociologique. Durkheim recrutou principalmente jovens normaliens, agrégés de filosofia e contou com Céléstin Bouglé, Henri Hubert, Marcel Mauss (sobrinho de Durkheim), Gaston Richard, e François Simiand entre seus mais importantes colaboradores iniciais ${ }^{23}$. Eles tornaram-se responsáveis por rubricas bibliográficas no interior da revista. Além disso, é importante frisar que ao contrário de Worms, Durkheim não procurou oferecer uma tribuna de expressão doutrinal a todos os que apelavam para a sociologia. Ele criou uma revista constituída essencialmente pelas análises bibliográficas críticas. Tratava-se de utilizar as pesquisas históricas, geográficas, psicológicas, etc., para criticar do ponto de vista da sociologia, do ponto de vista de um método sociológico, promovendo um "espírito sociológico", uma maneira de pensar, de raciocinar, que se pretendia original e estritamente científica. Segundo a fórmula de Durkheim, o procedimento seria "explicar o social pelo social”, isto é, explicar os fenômenos sociais com a ajuda de instrumentos teóricos e metodológicos propriamente sociológicos. Sobre esse consenso epistemológico se fundamentou o acordo entre esses homens.

Eis aqui os três adversários em presença. Todos conhecem o resultado da luta, inútil fazer durar o suspense: foi Durkheim quem se impôs.As 
razões dessa vitória só podem ser compreendidas, sem arriscar reduzir demais a realidade histórica, à combinação de quatro fatores: o intelectual, o institucional, o político e a dinâmica de grupo. Foi sobretudo a força intelectual e a dinâmica de grupo que faltaram a Worms, que não possuía programa pessoal ou coletivo. Sua revista e seus congressos refletem as tendências do momento, e neles cada autor apresentava seus pontos de vista pessoais em reuniões mundanas onde se aplaudia cortesmente. As simpatias teóricas pessoais de Worms iam em direção a um organicismo estrito e maximalista, que interpretava a sociedade como dotada de órgãos, funções, necessidades, doenças, exatamente como um organismo biológico individual (Organisme et société, 1896). Em meados dos anos 1890, essa foi uma teoria que passou da moda, ela fazia lembrar Spencer e era muito criticada. Enfim, Worms não conseguiu obter dos juristas a criação de cátedras de sociologia, nem mesmo para si próprio.

Em resumo, o fator institucional não contou aí senão parcialmente, uma vez que lhe conferiu a notoriedade mas não o reconhecimento acadêmico pessoal. Seu papel na organização, promoção e legitimação da sociologia é incontestável, porém Worms não contribuiu diretamente para a institucionalização da sociologia na universidade. O fator dinâmica de grupo, sendo muito fraco, Worms teve muitos relacionamentos mas não uma verdadeira equipe. $\mathrm{O}$ fator intelectual era muito desfavorável, e o político, quase neutro: Worms não parece ter se distinguido muito por suas tomadas de posição.

Por sua vez, Tarde havia tido uma bela carreira acadêmica e sua teoria da imitação havia feito a volta ao mundo. No entanto, na França, desde o final dos anos 1890, essa teoria começava a ser criticada, acusada de excessiva generalidade, não explicando muita coisa por querer tudo explicar. Guardadas as proporções (Tarde é visto como claramente superior a Worms), a teoria de Tarde também se ressentiu pouco a pouco da comparação com o trabalho de análise e crítica minuciosas feito por Durkheim e seus colaboradores.

Em suma, o fator institucional era favorável a Tarde durante todo o período, ao passo que o fator intelectual era muito favorável no início mas se desfez pouco a pouco. Quanto ao terceiro fator, a dinâmica de grupo, é nulo. Tarde era absolutamente solitário, nunca trabalhou verdadeiramente em equipe nem formou nenhum aluno, possuía muitas relações mas nenhuma disciplina. Já o fator político, que era favorável no início por sua coerência com a ideologia republicana entre 1885 e 1898, se anulou porque Tarde não se engajou o bastante durante o Affaire Drey- 
fus, tendo assinado somente uma petição, e por ter sempre ostentado sua relativa hostilidade ao socialismo. Esta seria uma vantagem nos meios acadêmicos, mas não junto à juventude filosófica.

O fator institucional não ea favorável a Durkheim, e contrariamente ao que se tem sempre escrito, Tarde era muito mais reconhecido que ele no final do século. Em 1897, Durkheim fracassou no Collège de France, e apenas em 1902 obteve uma cadeira na Sorbonne (como suplente), retornando a Paris para ser definitivamente titulado em 1906. O fator intelectual, no seu caso, conheceu três fases: muito favorável antes de 1895 , muito ruim em 1895-1897, melhorando sempre a partir de 1897-1898. O fator dinâmica de grupo era muito favorável e constitui a mais segura especificidade de Durkheim. Ele teve incontestavelmente a inteligência de compreender que a pesquisa científica deveria ser coletiva, quis dotar uma equipe de um programa de trabalho que se encarnou no recorte das rubricas do Année sociologique.

O fator político era igualmente muito favorável no seio da juventude intelectual: de um lado, a maioria da equipe de Durkheim era composta de jovens socialistas (Durkheim mesmo ficou afastado da política mas são conhecidas suas simpatias e sabe-se que era amigo pessoal de Jaurès), de outro lado, a totalidade de sua equipe era muito ativamente dreyfusarde. Pode-se mesmo dizer que o grupo de Durkheim foi sem dúvida o único grupo científico inteiramente engajado no Affaire Dreyfus. E foi nesta luta política que ele forjou suas solidariedades internas mais fortes. É certo que a equipe não teria sido tão unida sem esses combates políticos.

Pode-se dizer que Durkheim ganhou a parada a partir de cerca de 1902, data que traz consigo diversos sinais decisivos. Em primeiro lugar, o reconhecimento acadêmico, pois em 1902 ele obteve enfim a consagração institucional ao ser nomeado para a Sorbonne. Na mesma data, Marcel Mauss e Henri Hubert, dois de seus mais importantes colaboradores, obtiveram postos de ensino na EPHE. Em segundo lugar, chegaram ao fim as críticas clássicas: quando se lê em outras revistas, ano a ano, as resenhas de Année sociologique, constata-se que o tom crítico do início mudou, muitas vezes, a partir desta data. Nos discursos dos comentadores, por vezes até mesmo no de outros sociólogos (Worms, por exemplo), Durkheim passou a ser cada vez mais designado como "o chefe da escola sociológica francesa”, portanto ele se adiantou definitivamente sobre todos os seus rivais, em particular Tarde, que aliás morreu em 1904. A equipe de Année sociologique se ampliou com recrutamentos muito importantes 
que não passaram despercebidos. As duas alianças mais significativas foram as do lingüista Antoine Meillet em 1902 (ele abriu uma seção de "sociolinguística" na revista), e a do filósofo Lucien Lévy-Bruhl em 1903 (em seu livro La morale et la science des moeurs).

A institucionalização da escola de Durkheim teve muitas conseqüências para a sociologia. A primeira delas é que, contrariamente ao que desejava Worms, foi nas faculdades de Letras (e não de Direito) que a sociologia se desenvolveu. Por seu próprio percurso e por sua própria zona de influência, Durkheim claramente ancorou a sociologia nos cursos universitários ao lado da filosofia ${ }^{24} \mathrm{e}$, embora permanecesse sempre muito limitada, essa ancoragem não se desfará na França. Foi no interior da filosofia que a sociologia conquistou uma autonomia parcial e relativa pelo viés de um certificado de moral e de sociologia (1920); somente emancipando-se da filosofia, a sociologia pôde adquirir enfim, a partir dos anos 1950, sua autonomia universitária completa.

O grupo de Durkheim, tendo investido massivamente na análise das representações coletivas e das categorias de pensamento através da história dos mitos e das religiões, manteve desde sua origem laços muito estreitos com a seção histórica e sobretudo com a seção das ciências religiosas da EPHE. Esta instituição constituiu para os durkheimianos uma via de legitimação institucional de primeira importância e parte de uma fonte de recrutamento e zona de influência não menos importante ${ }^{25}$. Desde 1901, quando o jovem Mauss foi nomeado para a cadeira de "Religiões dos povos não-civilizados" (título que ele mesmo criticará), um laço essencial foi formalizado e não se rompeu. Nessa data, a EPHE acolheu também Hubert e I. Levy. Mais ainda, ela se tornou um lugar de recrutamento e influência, como o testemunha a integração progressiva na equipe durkheimiana, não somente de uma dezena de alunos de Mauss e Hubert, mas também alguns de seus colegas rapidamente interessados pela sociologia (Meillet, depois Moret, Fossey e Doutté).

Este último ponto levanta algumas observações sucintas sobre a influência exercida pela sociologia durkheimiana sobre outras disciplinas. Sabe-se que Durkheim por vezes tentou institucionalizar também a sociologia colocando-a em concorrência com outras disciplinas das faculdades de Letras, tais como a história e a geografia. Mais geralmente, o questionamento epistemológico sistemático das fronteiras disciplinares da sociologia foi um dos pontos fortes da equipe de Durkheim ${ }^{26}$. Em certos casos, esse questionamento praticamente não suscitou reação. Tratase de disciplinas sem dúvida institucionalmente muito distanciadas, co- 
mo a criminologia dos médicos ou mesmo a economia política. Mas em outros casos, os sociólogos durkheimianos conseguiram estabelecer um diálogo epistemológico de uma real intensidade e com efeitos por vezes importantes e duráveis no interior das disciplinas implicadas. A influência da sociologia sobre a história, a geografia, a psicologia, a lingüística e a etnologia é assim, em graus diversos, incontestável. Em muitos casos, esta influência se traduziu por alianças intelectuais e institucionais que, embora secundárias, podem ser incluídas no processo global de institucionalização da sociologia.

Essas alianças podem ter tido efeitos imediatos, porém no entreguerras elas tomaram sua verdadeira dimensão. Tanto na Sociedade de Psicologia (refundada em 1920) quanto no Instituto Francês de Sociologia (fundado em 1924), os sociólogos durkheimianos selaram contatos estreitos com uma parte dos psicólogos. Mais claramente ainda, a criação na Sorbonne do Instituto de Etnologia de Paris em 1925 foi o resultado de uma aliança de sociólogos com os etnólogos do Museu Nacional de História Natural, que nasceu bem antes da guerra. Esta aliança também beneficiou a sustentação de certos geógrafos próximos dos durkheimianos. Enfim, estes últimos exerceram uma influência intelectual maior sobre os historiadores franceses de sua geração, notadamente aqueles que formaram no fim dos anos 1920 a escola dos Annales.

É preciso ainda insistir no papel infeliz do acaso no processo de institucionalização da sociologia na França. $\mathrm{O}$ acaso está aqui representado pelo início da Primeira Guerra Mundial, desastrosa para o conjunto da juventude intelectual francesa, mas que parece ter atingido mais particularmente os sociólogos franceses e seus aliados mais próximos. No conjunto dos alunos de Durkheim, Mauss e Hubert, uma dezena de jovens pesquisadores promissores são mortos nos campos de batalha. Entre eles, o próprio filho de Durkheim desaparece, arrastando (por desgosto) à morte o chefe da sociologia francesa com 59 anos de idade. Afinal de contas, é uma hecatombe que a sociologia durkheimiana terá dificuldade em superar. De fato, no entreguerras, apesar da consagração de certos grandes autores como Mauss, Halbwachs, Granet ou ainda Simiand, apesar da importância do posto de Bouglé à École Pratique des Hautes Etudes, a sociologia perderá igualmente a força conquistadora que possuía antes da guerra. Para o essencial, ela manterá suas posições mas, com exceção de uma cátedra na nova faculdade de Letras de Strasbourg, em 1919, ela não progredirá no seio da universidade francesa. 


\section{NOTAS}

${ }^{1}$ As análises apresentadas neste texto constituem uma síntese atualizada de nosso livro, La découverte du social. Naissance de la sociologie en France (1870-1914). Paris: La Découverte, 1998. O leitor encontrará ali a integralidade das fontes primárias que são utilizadas implicitamente no presente trabalho. E-mail: mucchiel@ext.jussieu.fr. Tradução de Fernando Kolleritz.

${ }^{2}$ Analisamos aqui apenas o nascimento da sociologia universitária. Não se tratará nesta história de indivíduos, revistas, escolas, instituições que se desenvolveram de modos autônomos, à margem do sistema de ensino público superior. Por exemplo, não serão aqui abordados os discípulos de Frédéric Le Play, que pretendiam também constituir a "ciência social” e que possuíam suas próprias instituições, suas próprias redes e suas próprias perspectivas individuais. (KALOARA, B; SAVOYE, A. Les inventeurs oubliés. Le Play et ses continuateurs aux origines des sciences sociales. Paris: Champ Vallon, 1989; SAVOYE, A. Les débuts de la sociologie empirique (1830-1930). Paris: Méridiens Klincksieck, 1994).

${ }^{3}$ PETIT, A. Heurts et malheurs du positivisme. Philosophie des sciences et politique scientifique chez Auguste Comte et ses premieres disciples (1820-1900). Thèse de Doctorat d'État de l'Université Paris I, 1993.

${ }^{4}$ BECQUEMONT, D; MUCCHIELLI. L. Le cas Spencer. Religion, Science et politique au XIXème siècle. Paris: PUF, 1998.

${ }^{5}$ Estas análises beneficiaram-se de trabalhos anteriores sobre este assunto: GEIGER, R. René Worms, lorganicisme et l'organisation de la sociologie. Revue française de sociologie, 22,1972, pp. 345-360.; CLARK,T. N. Prophets and patrons. The French university and the emergence of the social sciences. Harvard University Press, 1973; BESNARD, Ph. (éd. ). The sociological domain. The durkheimians and the founding of French sociology. Cambridge: Cambridge University Press; Paris: Maison des sciences de l'homme,1983; NADAN, Y. The Durkheimian school. A systematic and comprehensive bibliography. Westport: Greenwood Press, 1977.

${ }^{6}$ PROST, A. Histoire de l'enseignement en France. 1800-1967. Paris: A. Colin,1968; KARADY, V. Durkheim, les sciences sociales et l'université: bilan d'un semi-échec. Revue française de sociologie, 20 (1) 1976, pp. 267-311; VERGER, J. Histoire des universités en France. Toulouse: Privat, 1986; WEISZ, G. The emergence of modern universities in France, 1863-1914. Princeton University Press, 1983.

${ }^{7}$ BRETON, Y.; LUFTALLA, M. (ed.). L'économie politique en France au XIXème siècle. Paris: Economica, 1991.

${ }^{8}$ Os trabalhos de história política e de história social sobre estas questões são numerosos demais para que se dêem aqui apenas uma ou duas referências. O leitor interessado reportar-se-á aos manuais mais recentes de história deste período.

${ }^{9}$ BECQUEMONT, D.; MUCCHIELLI, L. Op. cit.

${ }^{10}$ CLARK. Op. cit.

${ }^{11}$ GÜLICH, C. Die Durkheim schule und der franzosische solidarismus. Wiesbaden: Deutsher Universitätsverlag, 1991.

${ }^{12}$ REBÉRIOUX, M. Le socialisme français de 1871 à 1914. In: DROZ, J. (ed.). Histoire générale du socialisme. Paris: PUF, 1974, 2, pp. 138-235; PROCHASSON, C. Les intellectuels, le 
socialisme et la guerre, 1900-1938. Paris: Seuil, 1993; REBÉRIOUX, M.; CANDAR, G. (ed.). Jaurès et les intellectuels. Paris: Éditions Ouvrières, 1994.

${ }^{13}$ SMITH, R. The École Normale Supérieure and the Third Republic. New York, 1982; CHARLE, C. Naissance des intellectuels. 1880-1900. Paris: Minuit, 1990.

${ }^{14}$ DOWBIGGIN, I. La folie héréditaire (ou comment la psychiatrie française s'est constituée en un corps de savoir et de pouvoir dans la seconde moitié du XIXème siècle). Paris: E.P.E.L.,1993; RENNEVILLE, M. La médecine du crime. Essai sur l'émergence d'un regard médical sur la criminalité en France (1785-1885). Lille: Presses Universitaires du Septentrion, 1997.

${ }^{15}$ MUCCHIELLI, Laurent. Aux origines de la psychologie universitaire en France (18701900): enjeux intellectuels, contexte politique, réseaux et stratégies d'alliance autour de la Revue Pbilosophique de Théodule Ribot. Annals of Science, 55, 1998, pp. 2263-289.

${ }^{16}$ BLANCKAERT, Claude. L’anthropologie personifiée. Paul Broca ou la biologie du genre humain. In: BROCA, P. Mémoires d'anthropologie. Paris: Jean-Michel Place, 1989, pp. IXLIII; Idem. Fondements disciplinaires de l'anthropologie française au XIXème siècle. Perspectives historiographiques. Politix. Travaux de science politique, 29, 1995, pp. 31-54.

${ }^{17}$ KALUSZUNSKI, M. La criminologie en mouvement. Naissance et développement d'une science sociale en France à la fin du XIXème siècle. Autour des "Archives d'anthropologie criminelle" d'Alexandre Lacassagne. Thèse de l' Université Paris VII, 1988; MUCCHIELLI, L. Histoire de la criminologie française. Paris: L’Harmattan, 1994.

${ }^{18}$ CLARK, T.N. Gabriel Tarde on communication and social influence: selected papers. Chicago University Press, 1969. A Revue d'bistoire des sciences humaines consagrou, no seu número 200/3, um dossiê a "Tarde e a criminologia européia na virada do século".

${ }^{19}$ Os trabalhos sobre Durkheim são numerosos demais para serem citados todos aqui (além de nossa obra cf. a bibliografia do manual de STEINER, P. La sociologie de Durkheim. Paris: La Découverte, 1994). Lembre-se a referência de base que a biografia de LUKES, S. Émile Durkheim. His life and his work. London, Allen Lane, 1973, constitui ainda hoje. Mencione-se igualmente o interesse da revista anual Durkheimian studies/Études durkheimiennes que publica há perto de vinte anos documentos e comentários sobre a obra de Durkheim e dos durkheimianos. Assinale-se também as obras coletivas recentes consagradas ao centenário da Divisão do trabalho social (BESNARD, Ph; BORLANDI, M.; VOGT, P. ( eds.). Division du travail et lien social. La thèse de Durkheim un siècle après. Paris: PUF, 1993 ) e das Regras do método sociológico (BORLANDI, M.; MUCCHIELLI, L. La sociologie et as méthode. Les règles de Durkheim un siècle après. Paris: L'Harmattan, 1995).

${ }^{19}$ CLARK, T.N. Op. cit.; GEIGER, R. The development of French sociology: 1870-1905. Ph.D. University of Michigan, 1972.

${ }^{20}$ Existe nesse momento, na França, um interesse renovado por Tarde, mas que pouco se importa com a verdade histórica (MUCCHIELLI, L. (ed.). Gabriel Tarde et la criminologie au tournant du siècle. Revue d'bistoire des sciences humaines, 3, 2000.)

${ }^{21}$ ELLENBERGER, H. À la découverte de l'inconscient. Histoire de la psychiatrie dynamique. Villeurbanne: SIMEP Éditions, 1974; (reedição de PARIS; Fayard, 1994); CARROY, J. Hypnose, suggestion et psychologie. L'invention de sujets. Paris: PUF, 1991; CASTEL,Pierre-Henri. La querelle de l'hystérie. Paris: Presses Universitaires de France, 1998 
${ }^{22}$ BESNARD, Ph. La formation de l'équipe de l'Année sociologique. Revue françaisse de sociologie, 20 (1), 1979, pp. 7-31.

${ }^{23}$ Sobre Mauss (e seu grande amigo Hubert), consulte-se a biografia extremamente completa de FOURNIER, M. Marcel Mauss. Paris: Fayard, 1994. Sobre Simiand, reporte-se ao livro coletivo editado por GILLARD, L; ROSIER; M. (ed.). François Simiand (1873-1935). Sociologie, histoire, économie. Paris: Ed. des archives contemporaines, 1997. Sobre Halbwachs, reporte-se ao número especial editado por MUCCHIELLI, L. 1999. Bouglé espera ainda seu biógrafo.

${ }^{24} \mathrm{KARADY}$,V. Stratégies de réussite et modes de faire-valoir de la sociologie chez les durkheimiens. Revue française de sociologie, 20 (1), 1976, pp. 49-82 e Idem. Op. cit., 1979.

${ }^{25}$ MUCCHIELLI, L. Les durkheimiens et la Revue de l'histoire des religions (1896-1916): une zone d'influence méconnue. Durkheimian Studies, 4, 1998, pp. 51-72.

${ }^{26}$ Este é um ponto sobre o qual temos particularmente insistido em nossa síntese (MUCCHIELLI, L., La décowverte du social, cit.). Se as discussões com os historiadores, os geógrafos e os economistas eram bem conhecidas, aquelas com os antropólogos, psicólogos, crimonólogos e lingüistas eram menos. Em outra obra, tratamos também dos historiadores das religiões (MUCCHIELLI, L. Les durkheimiens et la Revue de l'histoire des religions, cit.). Um trabalho sistemático está por ser feito sobre as relações com os juristas. 